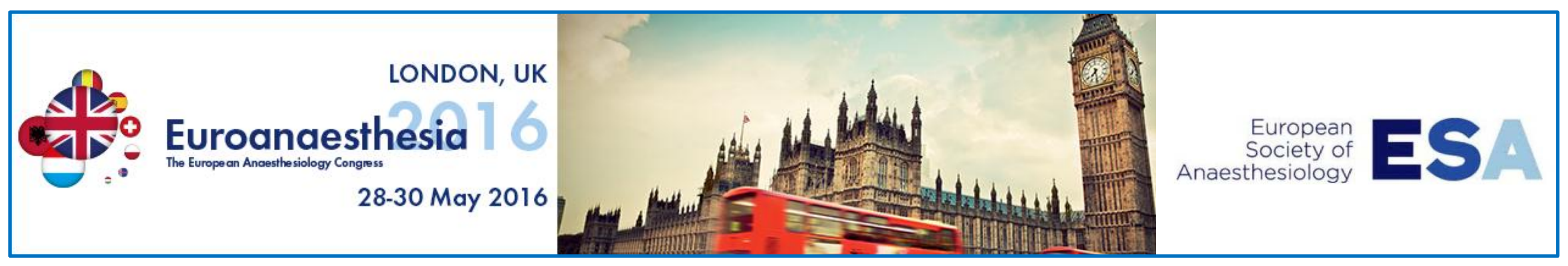

\title{
Preoperative anemia and postoperative morbidity in patients with hip fracture surgery
}

\author{
Bosch Duran L., Villar Colmenero T., Lamora Tost M., Castelltort Mascó L., Moltó Garcia \\ L., Bisbe Vives E.
}

\section{Parc de Salut Mar, Dept of Anaesthesiology, Barcelona, Spain}

Background and Goal of Study: About $30-40 \%$ of the patients with hip fracture have preoperative anemia and $10 \%$ severe anemia ${ }^{1}$. Preoperative anemia is an independent predictor of mortality in surgical patients ${ }^{2}$. The aim of this study is to determine the relationship between preoperative anemia and postoperative morbidity and which are the risk factors associated to preoperative anemia.

Materials and Methods: Institutional protocol for audit the hip fracture surgery procedure, involved in the quality program of our hospital. Were included all patients undergoing hip fracture surgery from June 1st to December 31th, 2014. We collected demographics data, comorbidity, oral anticoagulants or antiplatelet therapy, complete blood cell count and hematinic levels, delay of surgery, type of anesthesia, type of fracture, transfusion rate, hospital length stay and complications. The preoperative anemia cohort was compared against the cohort without anemia.

A descriptive and bivariate analysis was performed using the Student's T-test for quantitative variables and Pearson's chi-squared test for qualitative variables. A value of $\mathrm{p}<0.05$ was considered statistically significant.
Results and Discussion: We included 182 patients. Average age was $84 \pm 7$ years old, $80 \%$ women and $60 \%$ ASA III-IV. About $44 \%$ of patients had preoperative anemia and $20.7 \%$ preoperative iron deficiency (ferritin $<30 \mathrm{ng} / \mathrm{dl}$ ). The transfusion rate was $59 \%$. Preoperative anemia was significantly associated with female gender $(p=0.001)$ and low glomerular filtration rate $(81 \%$ anemic versus $35.6 \%$ without anemia; $p=0.001$ ), but not with age or worse ASA. Anemic patients were transfused twice $(p=0.001)$. The delay in surgery was higher preoperatively in anemic patients (3.8 versus 2.7 days; $p=0.001)$. The postoperative hemoglobin levels were significantly lower in preoperative anemic patients $(p=0.001)$. Anemic patients had more cardiac complications (28\% versus $15 \% ; p=0.004)$, but not respiratory, infectious, neurological or renal complications.

\begin{tabular}{|c|c|c|c|}
\hline DATA & $\begin{array}{l}\text { ANEMIC } \\
(\mathrm{N}=79)\end{array}$ & $\begin{array}{l}\text { NOT ANEMIC } \\
(\mathrm{N}=101)\end{array}$ & $\mathbf{P}$ \\
\hline AGE (years) & 85,4 & 83,5 & 0,05 \\
\hline GENDER (woman/man) & $72 / 7$ & $69 / 29$ & 0,001 \\
\hline ASA III-IV (\%) & 47,5 & 52,5 & 0,5 \\
\hline GRF $<60 \mathrm{ml} / \mathrm{min} / 1,73 \mathrm{~m}^{2}(\%)$ & 64 & 36 & 0,001 \\
\hline PREOPERATIVE Hb (g/dl) & 10,6 & 13,4 & 0,00 \\
\hline$+24 \mathrm{~h} \mathrm{Hb}(\mathrm{g} / \mathrm{dl})$ & 9 & 9,9 & 0,00 \\
\hline +72 h Hb (g/dl) & 8,8 & 9,3 & 0,00 \\
\hline TRANSFUSION (\%) & 83 & 48 & 0,00 \\
\hline SURGICAL DELAY TIME (days) & 3,8 & 2,7 & 0,00 \\
\hline $\begin{array}{l}\text { POSTOPERATIVE COMPLICATIONS (\%) } \\
\text { Cardiac } \\
\text { Respiratory } \\
\text { Surgical infections wound disturbances } \\
\text { Renal }\end{array}$ & $\begin{array}{l}28 \\
19,4 \\
4,2 \\
43,1\end{array}$ & $\begin{array}{l}15 \\
15,1 \\
6,5 \\
31,2\end{array}$ & $\begin{array}{l}\mathbf{0 , 0 0 4} \\
0,4 \\
0,4 \\
0,1\end{array}$ \\
\hline HOSPITAL LENGTH OF STAY (days) & 11,5 & 9,3 & 0,059 \\
\hline
\end{tabular}

Conclusions: The prevalence of preoperative anemia in hip fracture patients is high and conditioned a higher transfusion rate. Age, female gender and preoperative renal failure were predisposing factors but, surprisingly, not worse ASA. Preoperative anemia resulted in a significant increase of complications. Anemic patients tend to have a longer hospital stay. The treatment of anemia could improve perioperative transfusion rate and postoperative morbidity in this type of surgery.

\section{References:}

1. Wiles MD et al. Br J Anaesth. 2011;106(4):501-504.

2. Maxwell MJ et al. Br J Anaesth. 2008;101(4):511-517. 